\title{
Producción y consumo de Cerámica plomiza en Miguel Alemán y los complejos Conquista Campesina y Piñuela, Soconusco, Chiapas
}

\author{
Production and Consumption of Plumbate at Miguel Alemán, the Conquista Campesina and Piñuela \\ Complexes, Soconusco, Chiapas
}

\author{
Marx Navarro-Castillo
}

\begin{abstract}
Resumen: En este ensayo me enfoco en el análisis de la producción de cerámica y su consumo en el sitio Miguel Alemán y los complejos Conquista Campesina y Piñuela, en la región del Soconusco, Chiapas. El estudio de estas variables es una importante fuente de información para entender la organización de las economías antiguas y para la reconstrucción de formas de vida. Se realizó un estudio comparativo entre las vasijas consumidas y las producidas, tanto de manera global como en cada unidad doméstica. La riqueza de estos conjuntos cerámicos proveyó información sobre las diferencias jerárquicas entre grupos sociales y su distribución en el área estudiada.
\end{abstract}

Palabras clave: cerámica plomiza, economía doméstica, producción cerámica, consumo cerámico, especialización artesanal.

Abstract: This research is concerned with craft production and consumption. The analysis of these two aspects brings important information for understanding how ancient state cenomies worked and for reconstructing ancient life ways at Miguel Alemán, the Conquista Campesina Complex and the Piñuela Complex. I carried out a quantitative analysis of the number of pots consumed and produced in the overall area and also in each household cluster. The richness of these ceramic assemblages provided information about hierarchical differences between the social groups and how these groups were distributed within the area studied.

Keywords: Plumbate ceramic, household economy, ceramic production, ceramic consumption, craft specialization.

\footnotetext{
Marx Navarro Castillo, doctor en antropología por la New York State University at Albany, Estados Unidos. Profesor-investigador en la Facultad de Humanidades de la Universidad de Ciencias y Artes de Chiapas, México. Temas de especialización: Mesoamérica, Soconusco, análisis cerámico, arqueología de unidades domésticas. Correo electrónico: marx.navarro@fulbrightmail.orgy mn711295@albany.edu.

Enviado a dictamen: 10 de septiembre de 2014.

Aprobación: 17 de octubre de 2014.

Revisiones: 1 .
} 
L os exploradores Stephen y Catherwood fueron los primeros en dar referencia sobre la cerámica Tohil en una tumba en Zaculeu, Guatemala (Dutton, 1943: 3). Esta cerámica despertó gran interés entre los investigadores debido a la belleza estilística de las piezas, e identificar su lugar de origen pasó a ser uno de sus principales preocupaciones (ver foto 1). A partir de entonces, en Mesoamérica, se mencionaron muchos posibles sitios primarios de producción. Lothrop (1927), Thompson (1943) y posteriormente Bruhns (1980) propusieron El Salvador como el sitio de origen de la cerámica plomiza, e incluso Lothrop (1972) mencionó de manera específica la población de Suchitoto. En el caso de Bruhns (1980), además de proponer El Salvador, en específico el sitio de Cihuatán, también consideró la región central-sur de Veracruz como otra posible área de producción primaria de este tipo cerámico. Basó sus argumentos en la existencia en el lugar de tipos cerámicos con características "metálicas" como las que se observaban en la cerámica plomiza. Otro investigador que sugirió la costa del Golfo como área de origen de esta cerámica fue el arqueólogo Medellín Zenil (1960: 125), quien encontró cerámica con características "metálicas" en Polvaredas y Los Cerros, sitios datados hacia el período Clásico Tardío.

La incógnita sobre el origen de la cerámica plomiza fue parcialmente develada por Anna O. Shepard (1948), quien realizó un análisis extensivo en el área de Tajumulco, Guatemala, y propuso que este tipo de cerámica debió haber sido producido originalmente en el área que circundaba este sitio (Shepard, 1948). A esta propuesta se unió Edwin Shook (1965: 190), quien argumentó que la distribución de la cerámica San Juan plomizo durante el Clásico Tardío se extendía desde el noroeste del río Grijalva, en el centro de Chiapas, hasta la costa de Guatemala.

Lo propuesto tanto por Shepard (1948) como por Shook (1965) lo confirmaron las investigaciones realizadas por Hector Neff $(1984,1989,2001,2003)$, quien estaba especialmente interesado en encontrar las fuentes de arcilla y desgrasante utilizadas en la producción de este tipo de cerámica. Neff $(1984,1989)$ realizó un intensivo análisis de activación por neutrones a más de 450 especímenes de cerámica plomiza y desechos cerámicos asociados con su producción, procedentes del Soconusco. Este acercamiento, aunado al análisis y descripción de las formas y decoraciones observadas en la cerámica plomiza, fue determinante para señalar que sus variedades - Tohil y San Juan - fueron producidas con arcillas y desgrasantes provenientes de las áreas circundantes a los ríos Cahuacan, Suchiate, Naranjo y Tilapa (mapa 1).

\section{Cerámica plomiza}

Este tipo cerámico tuvo una gran distribución a partir el período Clásico Tardío (700-900 d.C.) y continuó al menos hasta el Posclásico Temprano (900-1200 d.C.). La cerámica plomiza ha sido hallada desde Nayarit (Mountjoy, 1991) hasta Costa Rica (Snarskis y Salgado, 1986), y desde Monte Albán (Bernal, 1986) hasta Tula (Bell y Ringle, 2007). Destaca el hecho de que generalmente se ha encontrado en contextos asociados con la élite en Mesoamérica, por lo cual era importante conocer su distribución en los sitios del Soconusco, donde fue producida y consumida a gran escala. En este sentido, Smith y Berdan (2003b: 24) señalaron que debió haber sido una mercancía clave hacia el período Posclásico, en Mesoamérica, junto con otros productos, como los granos de cacao y las campanas de cobre. En este aspecto es importante mencionar que el Soconusco fue también un área productora y exportadora de granos de cacao y una de las principales proveedoras de mercancías para el resto de Mesoamérica. Pero su importancia no se limita únicamente a los períodos Clásico Tardío y Posclásico Temprano, ya que dicha región fue testigo de importantes momentos en la historia de Mesoamérica, de manera que, de acuerdo con algunos autores, tal vez fue la primera área donde surgieron las sociedades complejas (Blake y Clark, 1999; Cheetham, 2006; Rosenswig, 2000) (ver mapa l). Posteriormente, durante el Posclásico Tardío, el Soconusco jugó un papel muy importante como tributario del imperio azteca, lo cual continuó durante el período colonial, especialmente debido a la producción de granos de cacao (Gasco, 2006). 
Los períodos Preclásico y Posclásico han sido ampliamente estudiados en el Soconusco, mientras que existe un vacío de conocimiento sobre el período Clásico, motivo por el cual en este trabajo se busca resarcir un poco esta falta de información a través del estudio de la producción, la distribución y el comercio de este tipo de cerámica, así como de su repercusión en la organización social, económica, y también política, en los asentamientos prehispánicos donde se producía.

\section{Marco teórico}

Al analizar la importancia del Soconusco, no sólo a nivel regional sino también interregional, me apoyé en la teoría del sistema-mundo como parte de mi marco teórico. Esta teoría (world-systems theory) fue desarrollada por Immanuel Wallerstein, en la década de los setenta del siglo pasado, quien centró sus bases en los eventos observados en las poblaciones europeas de los siglos XV y XVI. Wallerstein $(1974,1993)$ señaló que en el sistemamundo existe una gran división del trabajo que no es meramente funcional sino también geográfica, porque las labores económicas no se encuentran uniformemente distribuidas a lo largo de todo el sistema-mundo. Es así como Wallerstein (1974: 20) empleó términos como centro (core), periferia (peripheral areas) y áreas semiperiféricas (semi-peripheral areas). Esta división engloba una jerarquización de las labores ocupacionales, ya que existen zonas con mayor poder capital que otras y, por consiguiente, son las que detentan el control. Éste es el motivo por el que se observan marcadas diferencias económicas entre el centro y la periferia (Wallerstein, 1974:347-350). Es generalmente aceptado que los centros tomaron ventaja de los sitios periféricos para su propio desarrollo, aunque algunos investigadores señalan que dicha condición de explotación no fue tan estricta, aunque sí existía (Carmack y Salgado, 2006; Schortman y Urban, 1994).

El aporte de la arqueología al sistema-mundo consiste en demostrar las conexiones existentes entre poblaciones distantes con el fin de obtener diferentes productos, en sociedades lejanas en el tiempo, para comprobar la utilidad de esta teoría ampliamente utilizada hoy en día por sociólogos e historiadores. El este sentido, los estudios arqueológicos basados en esta teoría pueden convertirse en el "laboratorio" a partir del cual se observarían los cambios sociales a largo plazo.

El interés de los arqueólogos por buscar nuevas teorías para entender relaciones interregionales ha encontrado un potencial considerable al emplear la teoría del sistema-mundo como marco teórico, dado que implica una escala de análisis que incluye no sólo una entidad política o un grupo de ellas, sino el contraste entre el centro y la periferia. Esto es muy importante porque ayuda a determinar las relaciones sociales existentes, pues implica no sólo una separación espacial, sino una diferencia en la naturaleza de la organización social. Al mismo tiempo, nos da información sobre la estructura de las poblaciones estudiadas (Champion, 1989).

Mesoamérica ha sido un campo fecundo para el uso, el desarrollo y la prueba de la teoría sistema-mundo (Blanton y Feinman, 1984; Masson y Freidel, 2002; Smithy Berdan, 2000). Esto se debe a que los teóricos del sistemamundo arguyen que ciertas sociedades forman parte de redes integrales de intercambio, y estas redes repercuten en las organizaciones observadas en las mismas áreas (Kepecs y Kohl, 2003: 19). Lo anterior se advierte en el caso del Clásico Tardío y el Posclásico en Mesoamérica. Varias investigaciones señalan que esta teoría ha sido utilizada para entender relaciones macro-regionales (Carmack, 2013), y probablemente uno de los trabajos más importantes en este sentido fue el desarrollado por Smith y Berdan (2000), quienes en su investigación conjuntaron una serie de estudios a lo largo de diferentes regiones en Mesoamérica que florecieron durante el período Posclásico. Estos investigadores asumieron que durante ese período Mesoamérica estuvo organizada en grandes centros regionales y pequeñas entidades políticas, lo cual permitió un incremento en el volumen del intercambio de mercancías e información a larga distancia (Smith y Berdan, 2000: 284). Las interacciones sociales y comerciales durante el período Posclásico en Mesoamérica fueron las razones principales que consolidaron esta región como una economía común, así como una zona cultural (Smith y Berdan, 2003: 
3). La alta integración observada entre las entidades políticas del Posclásico seguramente tuvo sus bases en la organización existente en períodos previos, como el Clásico y el Preclásico, períodos durante los cuales también existieron intercambios comerciales y sociales a larga distancia. Un aspecto que distingue al Posclásico de los otros períodos fue el convertir los bienes de prestigio en bienes comerciales de lujo (Smith y Berdan, 2003a). Este aumento en el intercambio de productos facilitó la expansión e integración del sistema-mundo durante el período Posclásico. La cerámica plomiza, la cual es parte esencial de este estudio, fue considerada como una de las mercancías clave (key commodities), que ayudaron a la conformación del sistema-mundo Posclásico (Smith, 2003). Por la importancia de este tipo de cerámica se debe emplear un marco teórico que analice la producción artesanal, así como su injerencia en la organización social dentro de la población.

Un estudio completo de la producción artesanal debe describir diferentes aspectos de la producción, tales como la tecnología, la organización espacial, la organización temporal y la organización social con respecto a otras actividades e instituciones (Nash, 1970; Rice, 1987; Stark, 2007). En este marco, la producción de cerámica ha sido un tema arqueológico relevante desde hace décadas, por lo que un objetivo perseguido por los arqueólogos ha sido la identificación y clasificación de sus diferentes tipos y niveles de elaboración. Con respecto a este problema, Van der Leeuw $(1977,1984)$ analizó las diferentes tecnologías, materias primas y herramientas utilizadas por los alfareros, y en su trabajo pionero propuso la existencia de seis diferentes niveles de producción: doméstica (household), industria doméstica e industria individual (householdindustry and individual industry), industria de taller (workshop industry), industria de pueblo (village industry) $\mathrm{y}$, finalmente, industria a gran escala (large-scale industry) (Van der Leeuw, 1977: 70).

Peacock (1981), influido por Van der Leeuw, presentó su propia definición de los modos de producción de cerámica presentes en las sociedades de todo el mundo. Su clasificación consistió en producción doméstica (household production), industria doméstica (household industry), industria de taller (workshop industry) y fábrica (factory). Peacock (1981: 188), por otra parte, señaló que la producción doméstica se requiere sólo para satisfacer las necesidades del hogar, la tecnología utilizada es simple y la producción es esporádica. La segunda categoría, la industria doméstica, presenta algunas similitudes con la producción doméstica, pero las mujeres son responsables de la mayoría de la manufactura de bienes y sus productos finales, y éstos están destinados a ser intercambiados o negociados en un sistema de mercado. Con respecto a la industria de taller, la producción puede ser de medio tiempo, a diferencia de la producción doméstica y de la industria doméstica. El último modo de producción identificado por Peacock (1981) es la fábrica, que no se tendrá en cuenta en este análisis ya que requiere del uso de tecnología que no existía en las sociedades antiguas.

Unadelasprimerastipologíascreadas específicamente para entender la producción artesanal en Mesoamérica fue presentada por Santley et al. (1989) y consta de cuatro categorías diferentes: producción doméstica (household production), industrias domésticas (household industries), industrias de talleres (workshop industries) y, finalmente, producción de manufactura (manufactory production). Esta clasificación fue creada a partir de su trabajo en el sitio arqueológico de Matacapan, donde se produjeron bienes de prestigio de alta calidad que posteriormente fueron redistribuidos no sólo de manera regional, sino también interregional, a lo largo de Mesoamérica durante el período Clásico (Arnold y Santley, 1993).

En general, la producción artesanal especializada ha sido identificada en el registro arqueológico con base en la presencia de estándares durante el proceso de fabricación, lo que es consecuencia del aumento en la escala de producción. Esta propuesta se centra en la premisa de quela presencia de productos estandarizados está vinculada a la producción de gran escala, la cual también está relacionada con la aplicación de una uniformidad social y política observada en los bienes (Sinopoli, 2003). El grado de especialización también puede estar relacionado con la cantidad de tiempo dedicado a la artesanía y la cantidad producida (Shafer y Hester, 1991). La heterogeneidad/homogeneidad en la selección de la materia prima, la tecnología, la forma, 
las medidas y la decoración han sido analizadas con el fin de identificar el grado de especialización artesanal (Costin y Hagstrum, 1995; Tite, 2008), de manera que cuanto más tiempo dedica un alfarero a esa actividad más experiencia ganará al lograr que se cometan menos errores durante el proceso de producción (Michelaki, 2006). Longacre (1999) también considera la existencia de un vínculo entre especialización y estandarización, basado en su estudio de San Nicolás, en las Filipinas, de modo que pueden identificarse productos que presentan altos grados de estandarización ya que los artesanos emplearon una gama limitada de materiales y técnicas formalizadas o rutinarias que permitieron la elaboración de productos idénticos, o al menos muy parecidos. La importancia del estudio de la producción artesanal radica en su papel como parte fundamental del crecimiento económico de una sociedad.

\section{Análisis de la producción de cerámica}

La producción de cerámica es difícil de identificar arqueológicamente en comparación con otras industrias, como la producción lítica, porque la fabricación de cerámica es un proceso aditivo. Es decir, para la manufactura de una pieza de cerámica se agregan materiales, en contraste con la fabricación de herramientas líticas, en las que de un núcleo se substraen partes hasta conseguir la forma deseada. Con el fin de comprender mejor la organización y presencia de producción artesanal, los arqueólogos han empleado información etnográfica con base en la cual han interpretado los diferentes sistemas de producción (Arnold, 1985; Stark, 1985; Deal, 2007). Entre los elementos que los arqueólogos estudian se encuentran los materiales, la tecnología y el estilo observado en los productos finales, los desechos dejados durante su fabricación, así como los contextos físicos donde se recuperaron tanto los objetos, como los desechos de su producción (Costin, 2000; Arnold, 1991; Curet, 1993; Stark, 2007).

La producción de cerámica es una actividad en la que se siguen pasos específicos, los cuales dejan vestigios que pueden brindar información acerca del proceso.
La secuencia se inicia con la obtención de materias primas, evento que consiste en la búsqueda y obtención de arcillas, desgrasantes y materiales que sirven como combustible (Deal, 1998; Stark, 1995).

Conlafinalidaddeidentificar las áreas de producción, deben analizarse diversos restos arqueológicos. Mi investigación se basó en tres tipos principales de datos para la identificación de los lugares de producción. El primer conjunto de datos lo constituyen los instrumentos necesarios para la fabricación de cerámica, como herramientas, y las instalaciones necesarias para la cocción de la cerámica, como hornos o fogones (Deal, 1998; Arnold, 1991; Rice, 1981; Stark, 1995). El segundo tipo de evidencia es la obtenida por las frecuentes acciones repetitivas y también por los errores cometidos por los alfareros, pues dejaron materiales residuales que pueden ser utilizados por los arqueólogos. Entre estos subproductos se encuentran los restos de calcita y de arena utilizados en la preparación de la arcilla, así como la arcilla sobrante de las actividades de modelado y acabado, el derrame de pintura durante el baño o decoración de la cerámica y, finalmente, los tiestos o vasijas parcialmente completos desechados porque se quebraron durante su secado o cocción (Deal, 2007). Finalmente, las piezas completas serán el tercer tipo de información que será analizada.

Sin embargo, la relación entre los desperdicios y la producción cerámica en la mayoría de los casos no es sencilla. Stark (1995) sostiene que es importante la observación de altas densidades de tiestos y frecuencias excesivas de tipos cerámicos con el fin de identificar la presencia de un basurero de desperdicios cerámicos.

La cocción de los materiales es el proceso más impredecible de toda la producción artesanal de cerámica. En este sentido, aunque los alfareros fueran individuos altamente calificados, la cocción no pudo ser controlada en su totalidad, lo que dio lugar a que algunas piezas se quebraran (Arnold, 1991: 87); en la práctica, la mayoría de los desechos se crean debido a la ruptura durante la cocción (Stark, 1985). Las actividades de cocción pueden ser identificadas debido a la presencia de "enrojecimiento de la tierra, carbón vegetal y posiblemente depósitos de ceniza, roca 
fracturada térmicamente las cuáles fueron utilizadas para apuntalar vasijas y desechos de postes" (Deal, 1998: 75). La última categoría se compone de los productos finales, que proporcionan información acerca de las áreas de producción, la estandarización de productos, la elaboración de diseños y la cantidad de energía invertida (Arnold, 1991: 90).

Como se mencionó previamente, la existencia de piezas estandarizadas permite identificar la especialización artesanal, demodoquela estandarización es un elemento clave en los estudios de especialización. Como se mencionó, se considera en general que los alfareros con limitada tecnología para la producción en masa producen conjuntos más variables que aquellos artesanos que emplean herramientas estandarizadas o tecnologías de producción en masa. Mediante el uso de coeficientes de variación, se pone a prueba la existencia de un proceso de estandarización, dado que el coeficiente más alto de variación implica menos niveles de estandarización, lo que podría estar relacionado con una serie de diferencias en la producción, incluyendo la participación de un mayor número de artesanos (Masson y Rosenswig, 2005: 373). Por otra parte, se han utilizado diversas técnicas para identificar la estandarización en la cerámica, tales como histogramas y curvas de distribución (Rice, 1981), análisis de factores (Hagstrum, 1985) y las medidas de diversidad (Benco, 1988). En esta investigación se utilizaron los atributos morfológicos y tecnológicos propuestos por Costin y Hagstrum (1995), así como los atributos métricos y no métricos analizados por Masson y Rosenswig (2005). Los atributos morfológicos, al no ser métricos, no pueden ser cuantificados de manera numérica. Las cinco diferentes variables morfológicas estudiadas incluyeron las siguientes: tipo cerámico, forma del borde, forma del labio, forma de la vasija y color. Por lo que respecta a las variables tecnológicas, se analizaron tres diferentes características: diámetro de la boca de la vasija, grosor del borde y grosor del labio.

Antes de empezar con la descripción de las variables es importante señalar que la muestra estudiada fue de 3068 tiestos cerámicos, de cada uno de los cuales se analizaron tanto los atributos cuantitativos, como los cualitativos. Estas medidas fueron útiles al hacer estudios comparativos entre las muestras, ya que la variación o similitud entre ellas señaló los grados de especialización de los artesanos productores. Una vez comentado esto, pasaré a describir los atributos morfológicos: tipo cerámico, forma del borde, forma del labio, forma de la vasija y color.

Los tipos cerámicos fueron determinados empleando el sistema tipo-variedad. Si bien este estudio se enfocó en el análisis de la cerámica plomiza, era importante hacer un estudio comparativo con el resto de tipos de cerámica asociados y contemporáneos, de modo que fueron identificados un total de quince tipos cerámicos: café claro medio, café claro burdo, naranja burdo, rojo fino con hematita especular, gris fino, gris medio, negro fino, negro medio, crema fino, café obscuro fino, café obscuro medio, naranja quebradizo, café con engobe blanco, cerámica tipo iguana y plomiza.

Por lo que respecta a la descripción de los bordes, se tomaron en cuenta los trabajos realizados por Stark (1989), así como los efectuados por White y Henderson (2003). De esta manera se identificaron un total de dieciocho variables: evertido, vertical, invertido, evertido recto no-restricto d, evertido recto restricto e, evertido curvo-divergente restricto f, evertido curvo no restricto $g$, evertido curvo restricto $h$, vertical recto restricto i, vertical curvo-divergente no-restricto $\mathrm{j}$, vertical curvo no-restricto $\mathrm{k}$, vertical curvo restricto 1 , invertido recto no-restricto $\mathrm{m}$, evertido recto norestricto $n$, evertido curvo-divergente no-restricto o, evertido curvo-divergente restricto $\mathrm{p}$, evertido curvo restricto q, e invertido curvo no-restricto $r$.

Las categorías de los labios se organizaron en seis diferentes tipos: biselado hacia adentro, biselado hacia afuera, biselado en ambos lados, plano, redondeado y pellizcado.

Las formas de las vasijas también se analizaron, y se determinaron a través de las medidas de los radios de la altura y la anchura, así como también a partir del diámetro máximo y el de las bocas de las vasijas (Orton et al., 1993; Sabloff, 1975). Todas estas medidas pueden determinarse a partir de los bordes de las vasijas. De esta manera, se identificaron un total de nueve diferentes 
formas de vasijas como parte del conjunto cerámico hallado en Miguel Alemán, Conquista Campesina y Piñuela, entre las que se encontraron cuencos, incensarios, cilindros, platos, platos hondos, tinajas, ollas, tecomates y vasos. La categoría que presentó más variaciones y al final no fue determinante en el análisis fue el color. La variación de éste se debe a varias circunstancias, sobre todo al momento de cocción, ya que, al ser cocidas las piezas en hornos abiertos, es imposible el control del aire circundante y, por consiguiente, incluso vasijas del mismo grupo presentan coloración diferente. Por tal motivo, esta categoría fue desechada del análisis estadístico.

El análisis de las variables indicadas no sólo fue realizado para determinar la existencia de una especialización artesanal, sino que también brindó información sobre la organización social en aquellas zonas donde se consumió pero no se produjo cerámica. En el caso del sitio de Miguel Alemán, donde sólo se consumió cerámica plomiza pero no fueron identificadas áreas de producción, el análisis de los conjuntos cerámicos en cuanto a la calidad, cantidad y diversidad fue de suma importancia para conocer la jerarquización de las poblaciones. Como hemos mencionado, la cerámica plomiza fue encontrada únicamente en contextos de la élite, y fue importante conocer si ese patrón se cumplía para este sitio, donde la cerámica plomiza fue hallada en abundancia en nuestro recorrido de superficie.

\section{Miguel Alemán}

En el año 2008, junto con el Dr. Robert Rosenswig, de la Universidad de Albany, se realizó un recorrido de superficie no-sistemático del área que comprende el ejido Miguel Alemán, localizado en el municipio de Suchiate, Chiapas (ver mapa 2). Un patrón que resaltó durante el recorrido fue la gran cantidad de tiestos de cerámica plomiza observados en superficie. Sin embargo, fue en el año 2011 cuando se llevó a cabo un recorrido sistemático como parte del Proyecto de Reconocimiento Regional Izapa (PRRI). Los materiales recolectados en superficie durante este recorrido fueron de gran utilidad para identificar unidades habitacionales en el sitio. El criterio usado para su identificación fue la presencia de materiales cerámicos asociados a actividades propias de una casa, como cocinar, almacenar, servir y preparar comida (Jongsmay Greenfield, 2003: 21). También, la información obtenida a través de las excavaciones realizadas nos permitió identificar entierros y basureros, los cuales son buenos indicadores de unidades habitacionales (Flannery y Sabloff, 2009). De esta manera, los materiales identificados para su uso en actividades domésticas fueron tiestos de platos, ollas, cuencos, así como restos de materiales faunísticos (Killion et al., 1989).

Los conjuntos habitacionales estaban localizados a una distancia no mayor de cincuenta metros entre sí. Este patrón es consistente con lo propuesto por Flannery (1976), quien señaló que las unidades domésticas se encontraban separadas de otras contemporáneas por un área abierta cuya distancia variaba de veinte a cuarenta metros. Este patrón de distribución puede reflejar también vínculos económicos y sociales entre unidades domésticas dependientes. Los conjuntos cerámicos en Miguel Alemán se estudiaron empleando un análisis tridimensional, el cual incluyó la calidad, la cantidad y la diversidad de la cerámica consumida (Hirth, 1993; Smith, 1987; Starky Hall, 1993). Como se mencionó previamente, a lo largo de Mesoamérica la cerámica plomiza ha sido hallada en contextos asociados con la élite, razón por la cual era significativo determinar si este tipo cerámico fue consumido únicamente por la élite, o bien su consumo no estuvo asociado con un grupo en particular.

\section{Complejos Conquista Campesina y Piñuela}

Es importante señalar que el término "complejo" no está relacionado a complejos cerámicos, sino más bien a grupos de montículos que se encuentran cercanos entre sí, además de delimitados geográficamente, ya que se sitúan en isletas distintas dentro de los esteros. Tanto en el complejo Conquista Campesina como en el llamado Piñuela se observaron múltiples ocupaciones prehispánicas desde el Preclásico Temprano hasta 
el Clásico Terminal. La información analizada en esta sección fue recopilada a través del Proyecto Arqueológico Costa del Soconusco (PACS). El sitio Conquista Campesina se ubica cerca del ejido que lleva el mismo nombre; y el complejo Piñuela, cerca de la Ranchería El Sajío (ver mapa 2), ambos en la región del Soconusco, Chiapas. Para el estudio de estos sitios arqueológicos, la primera parte del proyecto empleó LIDAR —un acrónimo del inglés Light Detection and Ranging - para identificar montículos de tierra, los cuales fueron posteriormente analizados in situ para determinar si fueron ocupados durante la época prehispánica. Posteriormente, se emplearon técnicas de prospección remota, en específico radar de penetración terrestre (GPR) y magnetómetro para identificar anomalías como consecuencia de actividades asociadas a la producción de cerámica, tales como la cocción.

Fue así como los reconocimientos realizados tanto en superficie como en el subsuelo fueron útiles para identificar elementos relacionados con la producción de cerámica, tales como ceniza solidificada, arcilla, tiestos quemados o elementos piro-tecnológicos (Neff, 2014) (ver foto 2). Curet (1993: 428) identifica desechos cerámicos basados en tres categorías. La primera categoría está formada por desechos facto, los cuales son producto de accidentes ocurridos durante la cocción o la fractura de los productos finales. La segunda categoría agrupa aquellas piezas provenientes de vasijas que no fueron cocidas de manera total y no eran buenas para su uso o consumo. A su vez, estas piezas podían ser reutilizadas. La última categoría de desechos corresponde a piezas con cocción excesiva, lo cual provocó que se quemaran o deformaran.

\section{Importancia del estudio}

Los complejos Conquista Campesina y Piñuela presentan características muy especiales ya que son los únicos contextos en Mesoamérica de los que se conoce con certeza que fueron áreas de producción de cerámica plomiza. Por lo que respecta a Miguel Alemán, éste fue un sitio de consumo del cual se tiene suficiente información con base en el recorrido de superficie realizado. El análisis de los conjuntos cerámicos provenientes tanto de un sitio de consumo - Miguel Alemán-, como de las áreas de producción - complejos Conquista Campesina y Piñuela - constituye una buena fuente de información sobre la distribución de cerámica al permitirnos conocer más de cerca el sistema económico con relación a la cerámica plomiza.

Con base en las similitudes encontradas en los conjuntos cerámicos se puede señalar que los materiales consumidos en Miguel Alemán son los mismos que los producidos en Conquista Campesina y Piñuela. Sin embargo, la esfera de interacción de ambos sitios seguramente no estuvo restringida a un nivel local o regional, porque sin duda las condiciones ambientales jugaron un papel determinante para que establecieran relaciones también con el Soconusco y con otras regiones de Mesoamérica. El Soconusco se encuentra rodeado por cuerpos de agua que sin duda permitieron la movilidad de sus habitantes hacia regiones aledañas, lo que facilitó la interacción entre poblaciones y las transacciones no sólo comerciales, sino también culturales. Por este motivo no es de sorprender que la cerámica plomiza haya sido encontrada a lo largo y ancho de toda Mesoamérica.

Algo importante de aclarar es que no se puede asegurar que los habitantes de Miguel Alemán fueran los mismos que produjeron la cerámica plomiza en Conquista Campesina y Piñuela, pero sí se puede afirmar que estos tres sitios formaron parte de la misma red de interacción. Sin embargo, la idea de que podría tratarse de los mismos individuos no es tan absurda de acuerdo con los trabajos etnoarqueológicos conducidos en otras áreas de Mesoamérica. Dean E. Arnold (1985: 38), en su estudio sobre comunidades artesanales en el área maya, identificó que los artesanos obtenían la arcilla y los desgrasantes de lugares ubicados a una distancia que iba de uno a cincuenta kilómetros. Otro ejemplo es mencionado por Phillip Arnold (1991), cuyo trabajo en los Tuxtlas le permitió deducir que los artesanos obtenían la arcilla de dos lugares, uno localizado a 1.5 kilómetros y el otro a 2.5 kilómetros, lo cual equivalía a una hora de camino. Con relación al desgrasante, Arnold (1991: 24-25) observó que los habitantes obtenían este 
material a una distancia menor a un kilómetro, y la mayor distancia que recorrían los artesanos era de 2.42 kilómetros, donde se hallaba la fuente más cercana de combustible empleada para cocer cerámica.

Con base en estos ejemplos etnoarqueológicos, resaltan aún más las condiciones ambientales de los complejos Conquista Campesina y Piñuela, ya que tenían en abundancia fuentes de arcillas y combustible, además de contar con extensas áreas para producir cerámica plomiza. También es probable que los mismos habitantes de Miguel Alemán viajaran a Conquista Campesina o Piñuela, ya que únicamente se encontraban a aproximadamente trece kilómetros. Es decir, se podría tratar de una producción de tipo especializado estacional en la que los habitantes en ciertas temporadas del año, seguramente en la de secas, iban a estos sitios, producían la cerámica que requerían, y posteriormente regresaban a sus lugares de origen -Miguel Alemán en el caso que nos ocupa-. Si bien, como se mencionó, la distancia promedio es de trece kilómetros, se obtuvo información de pescadores de la ranchería el Sajío, quienes mencionaron que la distancia en cayuco podría completarse en dos horas empleando únicamente remos. Señaloquela producción es estacional pues alafecha no se ha encontrado material cerámico que pruebe la existencia de unidades habitacionales de tipo permanente tanto en el complejo Conquista Campesina, como en el complejo Piñuela. Considero que se trata de una producción especializada con base en la estandarización de las piezas estudiadas, ya que las variaciones en las medidas son mínimas y las formas son constantes.

\section{Análisis comparativo entre áreas de producción y de consumo}

Las variables tanto categóricas como numéricas fueron previamente descritas. Para facilitar el manejo y análisis de los datos, las variables numéricas - grosor del labio, grosor del borde y diámetro de la boca de la vasijase agruparon y estudiaron a través de una matriz de covarianza. Con base en la gráfica obtenida se pudo determinar que existió una clara relación entre las variables cuantitativas analizadas en este trabajo, ya que se observó un claro patrón en el cual todas las variables van hacia la misma dirección de manera positiva (ver figura 1).

Con el objetivo de saber si los materiales consumidos en Miguel Alemán fueron los mismos que los producidos en los complejos Conquista Campesina y Piñuela, se llevó a cabo un análisis de agrupamiento para así conocer la existencia de grupos y subgrupos homogéneos en los conjuntos cerámicos, dado que el análisis multivariado permite la creación de grupos bien definidos con base en similitudes. Estos grupos se obtienen a través del análisis de la naturaleza de las relaciones entre variables usando coeficientes de discriminación. De esta manera fue posible determinar si las variables eran independientes o si una o más variables eran dependientes, así como a qué nivel lo eran. En este sentido, es importante destacar que los resultados obtenidos a través de este examen multivariado son sumamente confiables (Brown et al. 2012; Johnson y Wichern, 2007). Debido a que nuestra base de datos se diseñó para atributos tanto categóricos como numéricos, lo más viable era emplear el coeficiente de Gower, ya que este análisis estadístico maneja datos de diferente naturaleza.

Tras calcular la distancia entre las observaciones, mediante el coeficiente Gower, era necesario usar un método que permitiera agruparlas, y una función que concentrara de manera jerárquica los valores obtenidos, en la cual los grupos se combinaran en categorías más grandes, pero al mismo tiempo se dividieran en subgrupos. La opción más viable fue usar el método Ward, el cual es un precursor de jerarquización que ayuda a optimizar algunos criterios para lograr la división de datos por agrupamientos jerárquicos (Johnson y Wichern, 2007: 693). Los resultados obtenidos a través del método Ward se visualizan empleando un dendrograma, donde los ejes verticales muestran el error de la suma de los cuadrados en el cual convergen (ver figura 2). Esto se calcula usando la función hclust del paquete "stats", del programa estadístico R: cumu <-hclust (mdist, method = "Ward"). Posteriormente el dendrograma se grafica usando este comando en R: plot (cumu, labels = FALSE, leaflab = c"none"). 


\section{Conformación de agrupamientos cerámicos}

Los agrupamientos se definieron empleando el método conocido como "el criterio de los codos" (Elbow Method). Este es un método visual en el cual los agrupamientos se dividen según la observación de ángulos en la gráfica, los cuales son causados por la variación entre los grupos. Con base en el análisis comparativo de las variables categóricas y numéricas obtenidas a través de los tiestos cerámicos, se identificaron seis diferentes agrupamientos. Es relevante apuntar que la presencia de un agrupamiento o conjunto no excluye la presencia de otro en el mismo contexto, lo cual nos habla de interacción entre los conjuntos.

El Conjunto l estuvo compuesto por 329 piezas cerámicas y fue encontrado en 105 contextos del total de 223 identificados en el área de consumo, por lo que representaba el 45.29\%. Así también este tipo de piezas se halló en todos los contextos identificados como áreas de producción. Este conjunto estuvo compuesto por once tipos cerámicos; la cerámica plomiza fue la predominante al representar el 80\% del conjunto cerámico. En cuanto a las formas de las vasijas, los cilindros fueron los más abundantes, con un total de 314 bordes asociados a este tipo de vasijas, por lo que representaron el $95.44 \%$ de la muestra. Los bordes de tipo vertical fueron los más comunes, observados en el $88.79 \%$ de las vasijas. En lo concerniente a los tipos de labios, la forma más abundante fue la redondeada, presente en el 34.24\% de las vasijas de este Conjunto 1, seguido por la forma biselada hacia adentro, que constituyó el $28.48 \%$ de la muestra.

Por lo que respecta al Conjunto 2, el más extenso de los seis identificados, se observó en 149 contextos provenientes del área de consumo y representó el 68.98\% del total de los sitios. De estos 149 contextos, dieciséis estuvieron asociados a montículos. Es importante mencionar que en todos los contextos de producción se encontraron materiales asociados al Conjunto 2. En este conjunto se encontraron doce diferentes tipos cerámicos; la cerámica plomiza fue la más abundante al representar el 86.04\% del conjunto. También en el Conjunto 2 se identificaron un total de ocho diferentes formas; la más común fue la de los cuencos, los cuales representaron el $96.42 \%$ del total. En relación con los bordes, la forma más común fue la evertida, que representó el 47.02\% del conjunto cerámico. El tipo de labio redondeado fue el más común, al igual que en el Conjunto 1, y se observó en el $45.35 \%$ de las vasijas.

El Conjunto 3 fue identificado en 113 contextos de consumo -el $50.67 \%$ del total-, trece de ellos asociados a montículos. De manera similar al patrón observado en los Conjuntos 1 y 2, todos los contextos de producción presentaron materiales asociados al Conjunto 3. Siete diferentes tipos cerámicos formaron parte de este conjunto; el más abundante fue el de la cerámica plomiza, que representó el $97.38 \%$ del total. De las siete formas de vasijas asociadas a este conjunto, las tinajas fueron las más comunes, las cuales representaron el $96.55 \%$ del total de las formas. Existió gran variedad en lo que respecta a las formas de los bordes, ya que se observaron catorce diferentes tipos, de las cuales, la más común fue la forma evertida curvo-divergente restricta f, que representó únicamente el $28.38 \%$ del total del conjunto cerámico. Esta alta variación también existió en los labios de las vasijas, ya que el tipo redondeado representó solamente el 50.92\% del conjunto cerámico.

El Conjunto 4 fue el más extenso ya que se identificó en 144 contextos; es decir, en el $66.67 \%$ del total de los sitios de consumo estudiados. Dieciocho de estos contextos estuvieron asociados a áreas de montículos. De forma similar al patrón observado para los Conjuntos 1, 2 y 3, todas las áreas de producción presentaron material cerámico asociado a este conjunto. En total fueron doce los tipos cerámicos identificados en el Conjunto 4; la cerámica plomiza fue la más común. Es importante señalar que en este conjunto se observó el porcentaje más bajo de este tipo cerámico, ya que únicamente representó el $52.72 \%$, y por consiguiente el tipo café claro medio incrementó su presencia hasta constituir el 32.19\% del conjunto cerámico. Se observó un mismo patrón al analizar las formas de las vasijas, ya que dos formas fueron las más abundantes, las ollas y las tinajas, que representaron el $54.62 \%$ y el $37.25 \%$, respectivamente. Es importante mencionar que estos dos tipos de vasijas pudieron haber sido utilizados 
para los mismos fines, ya que la única diferencia entre ambas formas es el tamaño de la boca de la vasija con relación a su máximo diámetro, que es más estrecho en el caso de las tinajas que en el de las ollas. Los bordes del tipo evertido curvo-divergente restricto $\mathrm{f} y$ evertido recto no-restricto d fueron los más comunes; representaron un $23.64 \%$ y un $20.53 \%$, respectivamente. En lo concerniente a los tipos de labios, de manera similar al patrón observado en los conjuntos previos, el tipo redondeado fue el más común ya que se observó en el $55.37 \%$ del conjunto cerámico.

El Conjunto 5 fue identificado en el $56.50 \%$ de los contextos de consumo; es decir, en 126 contextos, dieciséis de los cuales estuvieron asociados a montículos. De las siete áreas de producción, en seis se encontraron materiales asociados al Conjunto 5. Solamente cuatro tipos de cerámica se identificaron en este conjunto; la plomiza fue la más abundante al observarse en el 98.31\% de las muestras. La forma más abundante correspondió a los platos hondos, que representaron el $96.77 \%$ del conjunto cerámico. Existió también un marcado uso de dos diferentes tipos de bordes; los tipos evertido recto no-restricto n y evertido curvo-divergente no-restricto o fueron los más comunes al representar un $42.13 \%$ y un $43.20 \%$, respectivamente. Por último, los labios de tipo redondeado fueron los más frecuentes, ya que se observaron en el $62.67 \%$ de las vasijas.

Finalmente, el Conjunto 6 fue identificado en 143 contextos de consumo, el 64.12\% del total. Dieciséis de estos contextos estuvieron asociados a montículos. Por lo que respecta a las áreas de producción, cinco contextos de un total de siete presentaron materiales provenientes del Conjunto 6. El tipo cerámico más común de los siete identificados fue el plomizo, que representó el 98.31\% del conjunto. Únicamente cuatro formas de vasijas fueron identificadas, el número más bajo de todos los conjuntos analizados. La forma más abundante fue la de los platos planos, que constituyeron el 93.98\% del conjunto cerámico. A diferencia de otros conjuntos, el Conjunto 6 presentó un alto porcentaje de un solo tipo de bordes, en este caso el evertido curvodivergente no-restricto o, el cual se observó en el 82.89\% de las vasijas. Otra diferencia con relación a los otros conjuntos fue que el Conjunto 6 no presentó piezas con el tipo de labio redondeado como el más común, sino que el tipo de labio más abundante fue el biselado por ambos lados ya que estuvo presente en el $47.95 \%$ de las vasijas.

En cada uno de estos conjuntos se identificaron características únicas, las cuales ayudaron a efectuar las estadísticas a través del proceso previamente mencionado, además de identificar otros marcadores de jerarquización, por ejemplo, la arquitectura, ya que se tomó en cuenta la asociación con montículos de tierra.

\section{Conclusiones}

Una vez analizadas las áreas de consumo y producción, se logró identificar un patrón de distribución muy claro. Un rasgo definido fue que tanto las áreas de producción como las de consumo presentaron los mismos tipos cerámicos, formas, bordes y labios. Estas formas altamente estandarizadas podrían asociarse con un alto grado de especialización artesanal (Costin y Hagstrum, 1995; Rice, 1981, 1987; Roux, 2003). De esta manera, los seis conjuntos mencionados previamente muestran evidencias de una incipiente especialización, la cual aparentemente no representó ningún beneficio asociado a la posición social, o al menos esto no puede ser determinado únicamente a través del material cerámico, ya que se observó un consumo equitativo por parte de todos los segmentos de la población (Pool, 1992: 281).

Por último, es importante mencionar que solamente veinticinco contextos presentaron los seis conjuntos, y que estas locaciones pudieron definirse como unidades domésticas de la élite. Es importante apuntar que no todos los veinticinco contextos estuvieron asociados a montículos, así que esto también podría ser un indicativo de que la jerarquización social no estuvo tan marcada en el sitio arqueológico de Miguel Alemán. Con relación a las unidades domésticas que no presentaron los seis conjuntos, éstas se ubicaron cerca de otras que permitieron completar sus conjuntos cerámicos. Esta integración entre unidades domésticas sugiere la existencia de conjuntos habitacionales que se ubicaban cerca, lo que podría permitir una interacción continua, lo que concuerda con lo propuesto por Michael E. 
Smith (2010: 137) relativo a la "interacción cara-cara" característica de los barrios.

La ausencia de segregación en el consumo y la apenas perceptible variabilidad de los conjuntos cerámicos pueden estar asociadas con un control descentralizado sobre las fuentes y la tecnología cerámica (Pool y Bey III, 2007; Urban y Schortman, 2004). Por lo que respecta a las áreas de producción, se puede argumentar que en éstas se comerciaba lo producido con asentamientos vecinos. Esta red de intercambio a nivel local pudo también haber tenido un alcance regional y macroregional, ya que se encontró una vasija completa del tipo crema fino, muy parecida a los tipos provenientes de Escuintla, en el Pacífico guatemalteco (Oswaldo Chinchilla, comunicación personal 2014) (ver foto 3).

Este trabajo es un estudio sincrónico y diacrónico de la producción de cerámica, en especial la del tipo plomizo. Pocos estudios se han interesado en el análisis de las pequeñas poblaciones que comerciaron con valiosos objetos en Mesoamérica; los estudios más importantes al respecto son los realizados en Otumba, donde se comerció con obsidiana (Charlton et al., 1991, 1993), y en Matacapan (Arnold y Santley, 1993; Santley et al., 1989). ¿Qué hubiera sido de la economía brasileña sin el comercio del caucho a finales del siglo XIX e inicios de XX?, ¿o cómo afectó la producción de henequén en la economía no sólo de Yucatán, sino de todo el país? El estudio de las poblaciones prehispánicas analizadas en este artículo nos ayudó a entender las repercusiones a nivel regional de la producción de cerámica plomiza. Estos sitios debieron haber formado parte de la periferia, pues tanto su estructura social como las dimensiones de los mismos son muy limitadas y no concuerdan con las características propias de los centros. Es así como futuros estudios enfocados en el período Clásico en sitios arqueológicos de mayores dimensiones como Izapa serían trascendentales para proporcionar una imagen más completa de la organización macroregional 1 con base en el comercio de una mercancía clave, como la cerámica plomiza. Menciono Izapa de manera específica ya que posee características propias de los centros (cores), al contar con mayor cantidad poblacional y concentrar los poderes políticos (Smith y Berdan, 2003: 25). Esto es evidente con base en su arquitectura monumental y sus espacios claramente definidos. Sin embargo, su función como centro (core) es una simple especulación ya que al momento no existen trabajos en los que se haya estudiado a profundidad el periodo Clásico en estos sitios.

\section{Referencias bibliográficas}

Arnold, Dean E. (1985), Ceramic theory and cultural process. Nueva York, Cambridge University Press.

Arnold,PhilipJ.(1991),DomesticCeramicProductionandSpatial Organization: A Mexican Case Study inEthnoarchaeology. Nueva York, Cambridge University Press.

Arnold, Philip J. y Robert S. Santley (1993), "Household Ceramics Production at Middle Classic Period Matacapan". En Santley, R.S. y Kenneth G. Hirth (eds), Pre-Hispanic Domestic Units in Western Mesoamerica: Studies of the Household, Compound, and Residence. Boca Raton, Florida, CRC Press, pp. 227-248.

Benco, N. (1988), "Morphological Standardization: an Approach to the Study of Craft Specialization". En Kolb, C. y L. Lackey (eds.), A Pot for All Reasons: Ceramic Ecology Revisited. Philadelphia, Temple University, pp. 157-172.

Bernal, Ignacio (1986), "El valle de Oaxaca en el posclásico”. En Historia de México, vol. III. México, Salvat, pp. 99-116.

Bey III, George J. y William M. Ringle (2007), "From the Bottom Up: The Timing and Nature of the Tula Chichén Itzá Exchange". En Kowalski, J.K. y Cynthia Kristian-Graham (eds.), Twin Tollans. Chichén Itzá, Tula and the Epiclassic to Early Postclassic Mesoamerican World. Washington D.C., Dumbarton Oaks, pp. 377-428.

Blake, Michael y John E. Clark (1999), "The Emergence of Hereditary Inequality: the Case of Pacific Coastal Chiapas, Mexico". En Blake, M. (ed.), Pacific Latin America in Prehistory: the Evolution of Archaic and Formative Cultures. Pullman, Washington, WSU Press.

Blanton, Richard y Gary M. Feinman (1984), "The Mesoamerican World System". En American Anthropologist, núm. 86, pp. 673-682. 
Brown, Bruce L., Suzanne B. Hendrix, Dawson W. Hedges y Timothy B. Smith (2012), Multivariate Analysis for the Biobehavioral and Social Sciences. A graphical Approach. Hoboken, New Jersey, WILEY.

Bruhns, Karen Olsen (1980), "Plumbate Origins Revisited". En American Antiquity, vol. 45, núm. 4, pp. 845-848.

Carmack, Robert M. (2013), Anthropology and Global History: From Tribes to the Modern World System. Plymouth, Reino Unido, AltaMira Press.

Costin, Cathy L. (2000), "The Use of Ethnoarchaeology for the Archaeological Study of Ceramic Production". En Journal of Archaeological Method and Theory,vol. 7, núm. 4, pp. $377-403$.

Costin, Cathy L. y Melissa B. Hagstrum (1995), "Standardization, Labor Investment, Skill, and the Organization Ceramic Production in Late PreHispanic Highland Peru". En American Antiquity, vol. 60, núm. 4, pp. 619-639.

Curet, Antonio (1993), "Regional Studies and Ceramic Production Areas: An Example from La Mixtequilla, Veracruz, Mexico". En Journal of Field Archaeology, vol. 20, núm. 4, pp.427-440.

Champion, Timothy C. (1989), "Introduction". En Champion, T.C. (ed.), Centre and Periphery: Comparative Studies in Archaeology. Nueva York, Routledge, pp. 1-2l.

Charlton, Cynthia O., Thomas H. Charlton y Deborah L. Nichols (1993), "Aztec Household-Based Craft Production: Archaeological Evidence from the CityState of Otumba, Mexico". En Santley, R.S. y Kenneth G. Hirth (eds.), Pre-Hispanic Domestic Units in Western Mesoamerica: Studies of the Household, Compound, and Residence. Boca Raton, Florida, CRC Press, pp. 147-171.

Charlton, Thomas H., Deborah L. Nichols y Cynthia Otis Charlton (1991), "Aztec Craft Production and Specialization: Archaeological Evidence from the CityState of Otumba, Mexico". En World Archaeology, vol. 23, núm. 1, pp. 98-114.

Cheetham, David (2006), "America's First Colony? A Possible Olmec Outpost in Southern Mexico". En Archaeology, núm. 59, pp. 42-46.

Deal, Michael (1998), Pottery Ethnoarchaeology in the Central Maya Highlands. Salt Lake City, University of UTAH Press.
Deal, Michael (2007), “An Ethnoarchaeological Perspective on Local Ceramic Production and Distribution in the Maya Highlands". En Bey III, George y Christopher A. Pool (eds), Pottery Economics in Mesoamerica. Tucson, University of Arizona Press, pp. 39-59.

Dutton, Bertha P. (1943), A History of Plumbate Ware. Santa Fe, s.e.

Flannery, Kent V. (1976), The Early Mesoamerican Village. Nueva York, Academic Press.

Flannery, Kent V. y Jeremy A Sabloff (2009), The Early Mesoamerican Village. California, Left Coast Press.

Gasco, Janine L. (2006), "The Political Geography of the Province of Soconusco in the Late Postclassic and Early Colonial Periods". En Okoshi Harada, T., Ana Luisa Izquierdo y Lorraine A. Williams-Beck (eds.), Nuevas perspectivas sobre la geografía política de los mayas. México, UNAM/Universidad Autónoma de Campeche/ FAMSI, pp. 183-207.

Hagstrum, Melissa G. (1985), "Measuring Prehistoric Ceramic Craft Specialization: a Test Case in the American Southwest. En Journal of Field Archaeology, núm. 12, pp. 65-75.

Hirth, Kenneth (1993), "The Household as an Analytical Unit: Problems in Method and Theory". En Santley, R.S. y Kenneth G. Hirth (eds.), Pre-Hispanic Domestic Units in Western Mesoamerica: Studies of the Household, Compound, and Residence. Boca Raton, Florida, CRC Press, pp. 21-36.

Instituto Nacional de Estadística y Geografía (2013), Anuario estadístico y geográfico de Chiapas, México. Aguascalientes, INEGI.

Johnson, Richard A. y Dean W. Wichern (2007), Applied Multivariate Statistical Analysis. Upper Saddle River, New Jersey, Pearson/Prentice Hall.

Jongsma, T, y H.J. Greenfield (2003), "The Household Cluster Concept in Archaeology: A Brief Review". En Nikolova, Lolita (ed.), Early Symbolic Systems for Communication in Southeast Europe, vol. 1. British Archaeological Reports, International Series, vol. 1139, pp. 21-24.

Kepecs, Susan y Philip Kohl (2003), “Conceptualizing Macroregional Interaction. World-Systems Theory and the Archaeological Record". En Smith, M.E. y 
Frances Berdan (eds.), The Postclassic Mesoamerican World. Salt Lake City, University of Utah Press, pp. 14-20..

Longacre, William A. (1999), "Standardization and Specialization: What's the Link?” En Skibo, J.M. y Gary M. Feinman (eds.), Pottery andPeople. A Dynamic Interaction. Salt Lake City, University of Utah Press, pp. 44-58.

Lothrop, Samuel K. (1927), "Pottery Types and Their Sequence in El Salvador". En Indian Notes and Monographs, vol. 1, núm.4, pp. 165-220. Nueva York, Museum of the American Indian/Heye Foundation.

Masson, Marilyn A. y David A. Freidel (eds.) (2002), Ancient Maya Political Economies. Walnut Creek, California, Altamira Press.

Masson, Marylin y Robert M. Rosenswig (2005), "Production Characteristics of Postclassic Maya Pottery from Caye Coco, Northern Belize". En Latin American Antiquity, vol. 16, núm. 4, pp. 355-384.

Medellín Zenil, Alfonso (1960), Cerámicas del Totonacapan. Xalapa, Veracruz, Universidad Veracruzana/Instituto Nacional de Antropología.

Michelaki, Kostalena (2006), Household Ceramic Economies. Production and Consumption of Household Ceramics among the Maros Villagers of Bronze Age Hungary. Oxford, Archaeopress.

Mountjoy, Joseph B. (1991), "West Mexican Stelae from Jalisco and Nayarit". En Ancient Mesoamerica, vol. 2, núm. 1, pp. 21-33.

Nash, June (1970), In the eyes of the ancestors. New Haven, Yale University Press.

Neff, Hector (1984), The Developmental History of the Plumbate Pottery Industry in the Eastern Soconusco Region, A.D. 600 through A.D. 1250. Santa Bárbara, Universidad de California.

Neff, Hector (1989), "Origins of Plumbate Pottery Production". En Voorhies, B. (ed.), Ancient Trade and Tribute. Economies of the Soconusco Region of Mesoamerica. Salt Lake City, University of Utah Press, pp. 175-193.

Neff, Hector (2001), Production and Distribution of Plumbate Pottery: Evidence from a Provenance Study of the Paste and Slip Clay Used in a Famous Mesoamerican Tradeware. S.l., FAMSI.

Neff, Hector (2003), “Analysis of Mesoamerican Plumbate Pottery Surfaces by Laser Ablation Inductively
Coupled Plasma-Mass Spectrometry (LA-ICP-MS)". En Journal of Archaeological Science, núm. 30, pp. 21-35.

Neff, Hector (2014), Proyecto Arqueológico Costa del Soconusco (PACS): informe de la segunda temporada de campo y solicitud depermiso. México, Instituto Nacional de Antropologia e Historia.

Orton, Clive, Paul Tyers y Alan Vince (1993), Pottery in Archaeology. Cambridge, Reino Unido, Cambridge University Press.

Peacock, D.P.S (1981), "Archaeology, Ethnology and Ceramic Production". En Howard, H. y Elaine L. Morris (eds.), Production and Distribution: A Ceramic Viewpoint. Oxford, B.A.R., pp. 187-194.

Pool, Christopher A. (1992), Integrating Ceramic Production and Distribution. Ceramic Production and Distribution: An Integrated Approach. Boulder, Colorado, Westview Press, pp. 275-313.

Pool, Christopher A. y George J. Bey III (eds.) (2007), Pottery Economics in Mesoamerica. Tucson,University of Arizona Press.

Rice, Prudence M. (1981), "Evolution of Specialized Pottery Production: A Trial Model". En Current Anthropology, vol. 22, núm. 3, pp. 219-240.

Rice, Prudence M. (1987), Pottery Analysis: A Sourcebook. Chicago, University of Chicago Press.

Rosenswig, Robert M. (2000), "Some Political Processes of Ranked Societies". En Journal of Anthropological Archaeology, núm. 19, pp. 413-460.

Roux, Valentine (2003), "Ceramic Standardization and Intensity of Production: Quantifying Degrees of Specialization”. En American Antiquity, vol. 68, núm. 4, pp. 768-782.

Sabloff, Jeremy A. (1975), "Excavations at Seibal: Ceramics". En Memoirs of the Peabody Museum of Archaeology and Ethnology, vol. 13, núm. 2.

Santley, Robert S., Phillip J. Arnold III y Christopher A. Pool (1989), "The Ceramics Production Systemat Matacapan, Veracruz, Mexico". En Journal of Field Archaeology, vol. 16, núm. 1, pp. 107-132.

Schortman, Edward M. y Patricia Urban (2004), "Modeling the Roles of Craft Production in Ancient Political Economies". En Journal of Archaeological Research, vol. 12, núm. 2, pp. 185-226. 
Shafer, Harry J. y Thomas R. Hester (1991), "Lithic Craft Specialization and Product Distribution at the Maya Site of Colha, Belize". En World Archaeology, vol. 23, núm. 1, pp. 79-9l.

Shepard, Anna O. (1948), Plumbate: A Mesoamerican Tradeware. Washington: Carnegie Institution of Washington.

Shook, Edwin M. (1965), "Archaeological Survey of the Pacific Coast of Guatemala”. En Handbook of Middle American Indians, vol. 2. Austin, University of Texas, pp. 180-194,

Sinopoli, Carla M. (2003), The Political Economy of Craft Production: Crafting Empire in South India, c.1350-1650. Cambridge, Cambridge University Press.

Smith, Michael E. (1987), "Household Possessions and Wealth in Agrarian States: Implication for Archaeology". En Journal of Anthropological Archaeology, núm. 6, pp. 297-335.

Smith, Michael E. (2003), "Key Commodities". En Smith, M.E y Frances Berdan (eds.), The Postclassic Mesoamerican World. Salt Lake City, University of Utah Press, pp. 117-125.

Smith, Michael E. (2010), "The Archaeological Study of Neighborhoods and Districts in Ancient Cities. En Journal of Anthropological Archaeology, vol. 29, núm. 2, pp. 137-154.

Smith, MichaelE.y Frances Berdan (2000), "The Postclassic Mesoamerican World System”. En Current Anthropology, núm.4l, pp. 283-286.

Smith, Michael E. y Frances Berdan (2003b), "Spatial Structure of the Mesoamerican World System". En Smith, M.E. y F.F. Berdan (eds.), The Postclassic Mesoamerican World. Salt Lake City, University of Utah Press, pp. 21-31.

Snarskis, Michael J.y Silvia Salgado G. (1986), "Stratigraphic Excavation of Plumbate Pottery at the Nacascolo Site, Costa Rica”. En Mexikon, vol. 8, núm. 6, pp. 128-132.

Stark, Barbara L. (1985), "Archaeological Identification of Pottery-Production Locations: Ethnoarchaeological and Archaeological Data in Mesoamerica". En Nelson, B.A. (ed.), Decoding Prehistoric Ceramics. Illinois, Southern Illinois University at Carbondale/Center for Archaeological Investigations, pp. 158-194.
Stark, Barbara L. (1995), "Problems in Analysis of Standardization and Specialization in Pottery". En Mills, B.J. y Patricia L. Crown (eds.), The Organization of Ceramic Production in the American Southwest. Tucson, University of Arizona Press, pp.231-267.

Stark, Barbara L. (2007), "Pottery Production and Distribution in the Gulf Lowlands". En Bey III, G.y Christopher A. Pool (eds.), Pottery Economics in Mesoamerica. Tucson, University of Arizona Press, pp. 147-183.

Stark, Barbara L. y Barbara Ann Hall (1993), "Hierarchical Social Differentiation Among Late to Terminal Classic Residential Location in La Mixtequilla, Veracruz, Mexico". En Santley, R.C.y Kenneth G. Hirth (eds.), Pre-Hispanic Domestic Units in Western Mesoamerica. Boca Raton, Florida, CRC Press.

Thompson, John Eric Sidney (1943), "A Trial Survey of the Southern Maya Area". En American Antiquity, vol. 9, núm. 1, pp. 106-134.

Tite, M.S. (2008), "Ceramic Production, Provenance and Use. A Review". En Archaeometry, vol. 50, núm. 2, pp. 216-231.

Van der Leeuw, S.E. (1977), "Towards a Study of the Economics of Pottery Making. En Cingula, núm. 4, pp. 68-76.

Van der Leeuw, S.E. (1984), "Pottery Manufacture: Some Complications for the Study of Trade". En Rice, P.M. (ed.), Potsand Potters. Current Approaches in Ceramic Archaeology. Los Angeles, University of California, pp. 55-69.

Wallerstein, Immanuel (1974), The Modern World-System. Nueva York, Academic Books.

Wallerstein, Immanuel (1993), "World System Versus World-Systems”. En Frank, A.G. y Barry K. Gills (eds.), The World System: Five Hundred Years or Five Thousand? Londres, Routledge, pp. 292-296.

White, Joyce C. y William Henderson (2003), "Pottery Anatomy: Review and Selection of basic nomenclature as a step toward a searchable rim form database for the Sakon Nakhon Basin". En Indo-Pacific Prehistory Association Bulletin, 1(23), pp. 35-49. 
Figura 1. Matriz de dispersión de los datos cuantitativos analizados en esta investigación
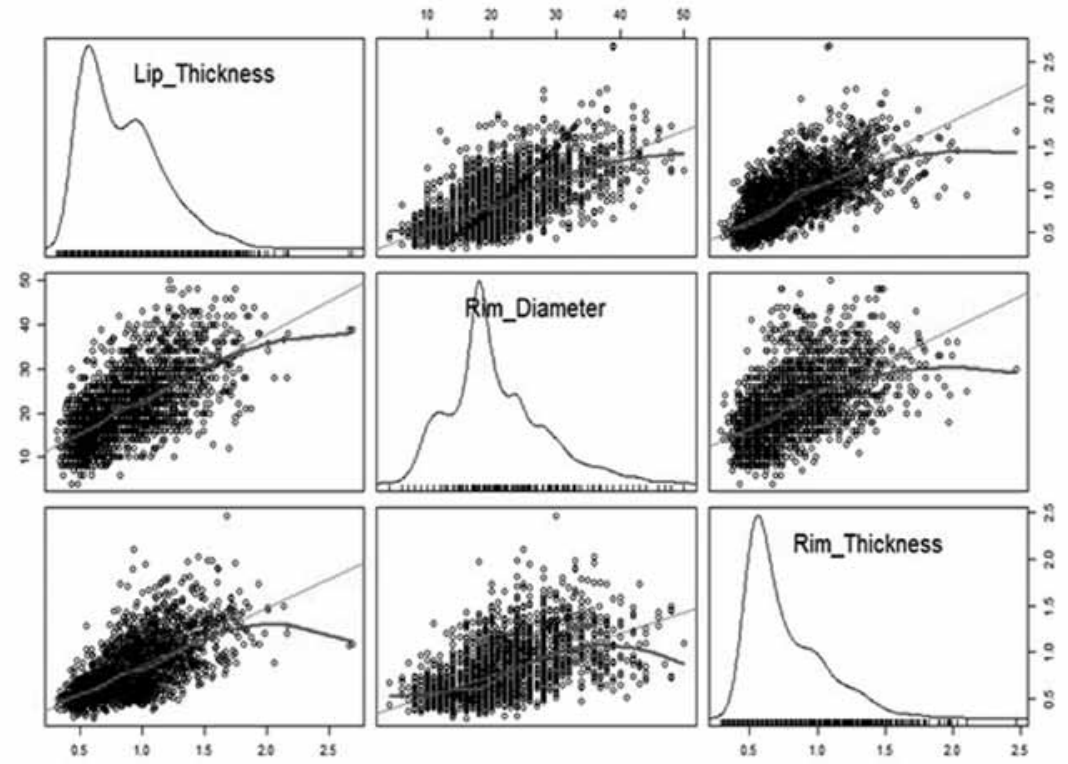

Fuente: gráfica obtenida a través del análisis estadísticos de datos usando el software R. Elaboración propia.

Figura 2. Seis conjuntos identificados mediante el método Ward

\section{Cluster Dendrogram}

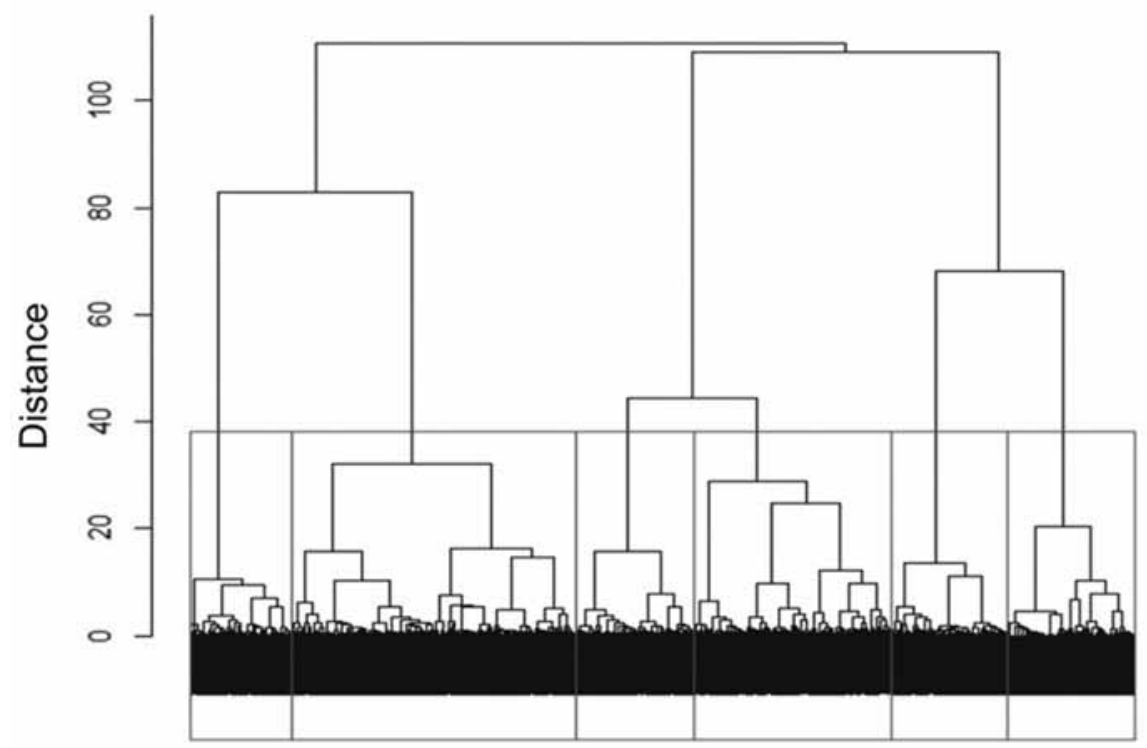

Fuente: gráfica obtenida a través del análisis estadístico de datos usando el software R. Elaboración propia. 
Foto 1. Cilindro plomizo con decoración incisa de un animal, probablemente un tlacuache

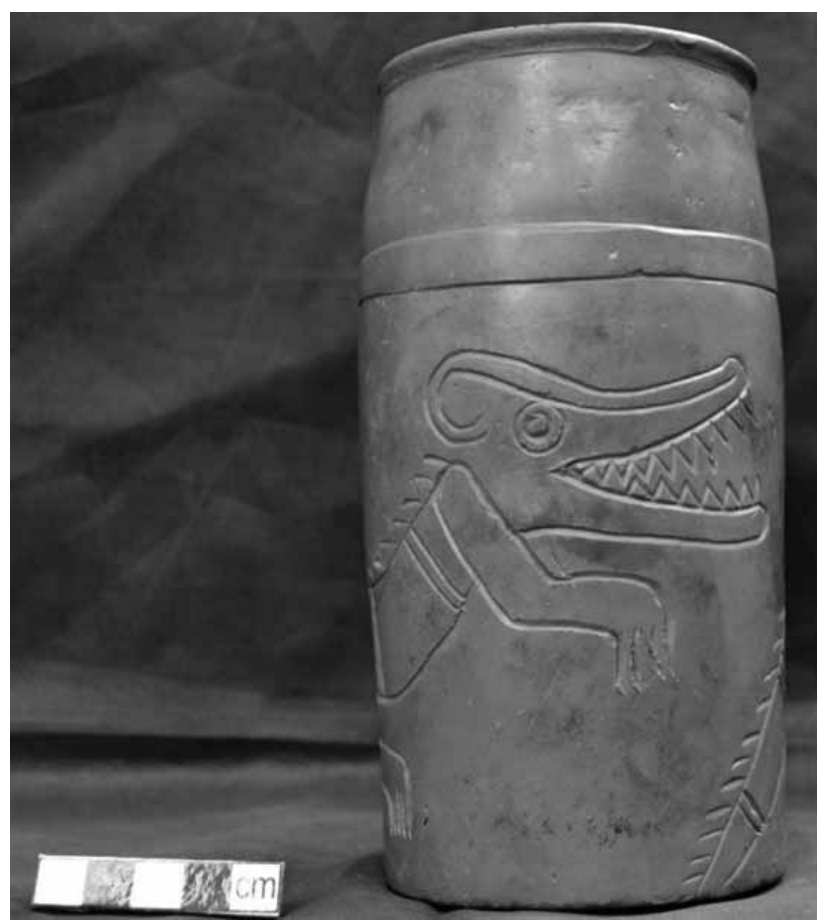

Fuente: pieza obtenida durante excavaciones en Miguel Alemán.

Foto 2. Elemento pirotecnológico identificado en complejo Conquista Campesina en el Área 2 S2E0

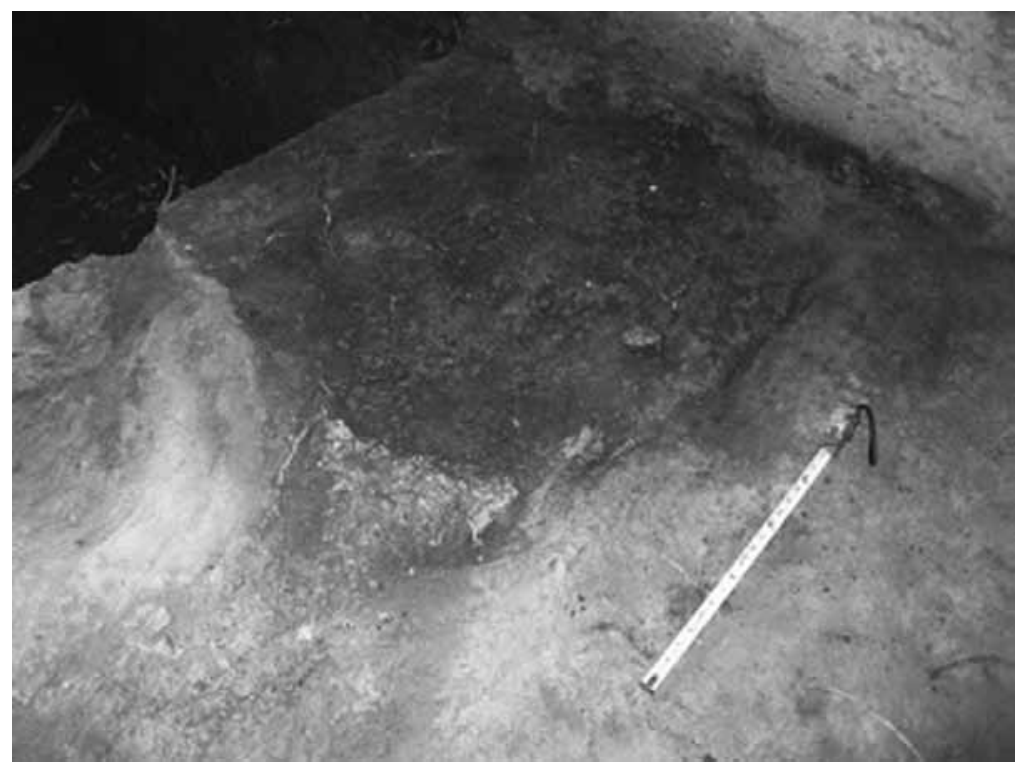

Fuente: imagen cortesía del Proyecto Arqueológico Costa del Soconusco (Hector Neff, director). 
Foto 3. Vaso crema fino encontrado en Miguel Alemán (reverso)

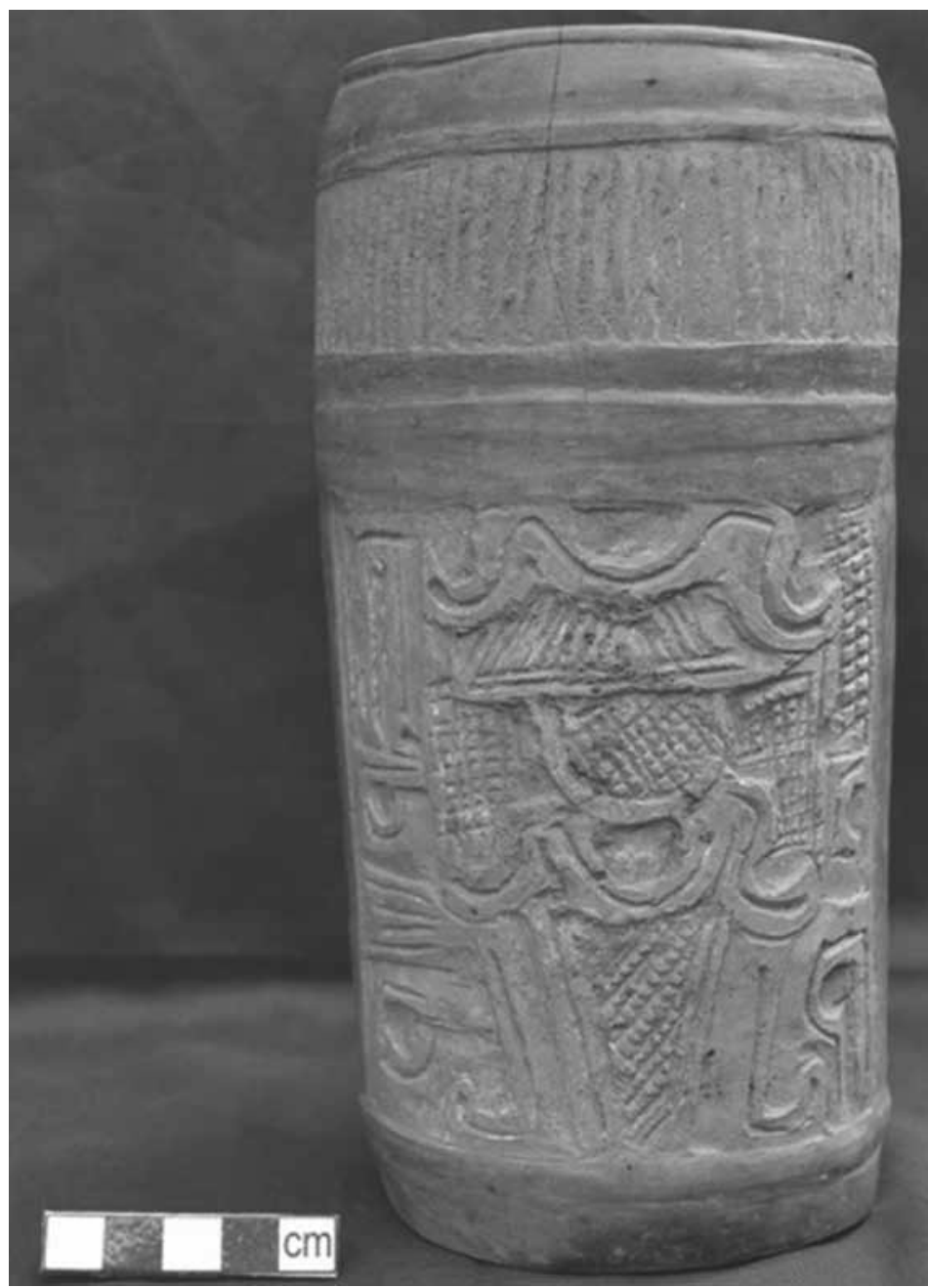

Fuente: pieza obtenida durante las excavaciones en Miguel Alemán. 
Mapa 1. Mapa de las áreas de distribución de los tipos tohil y San Juan plomizo

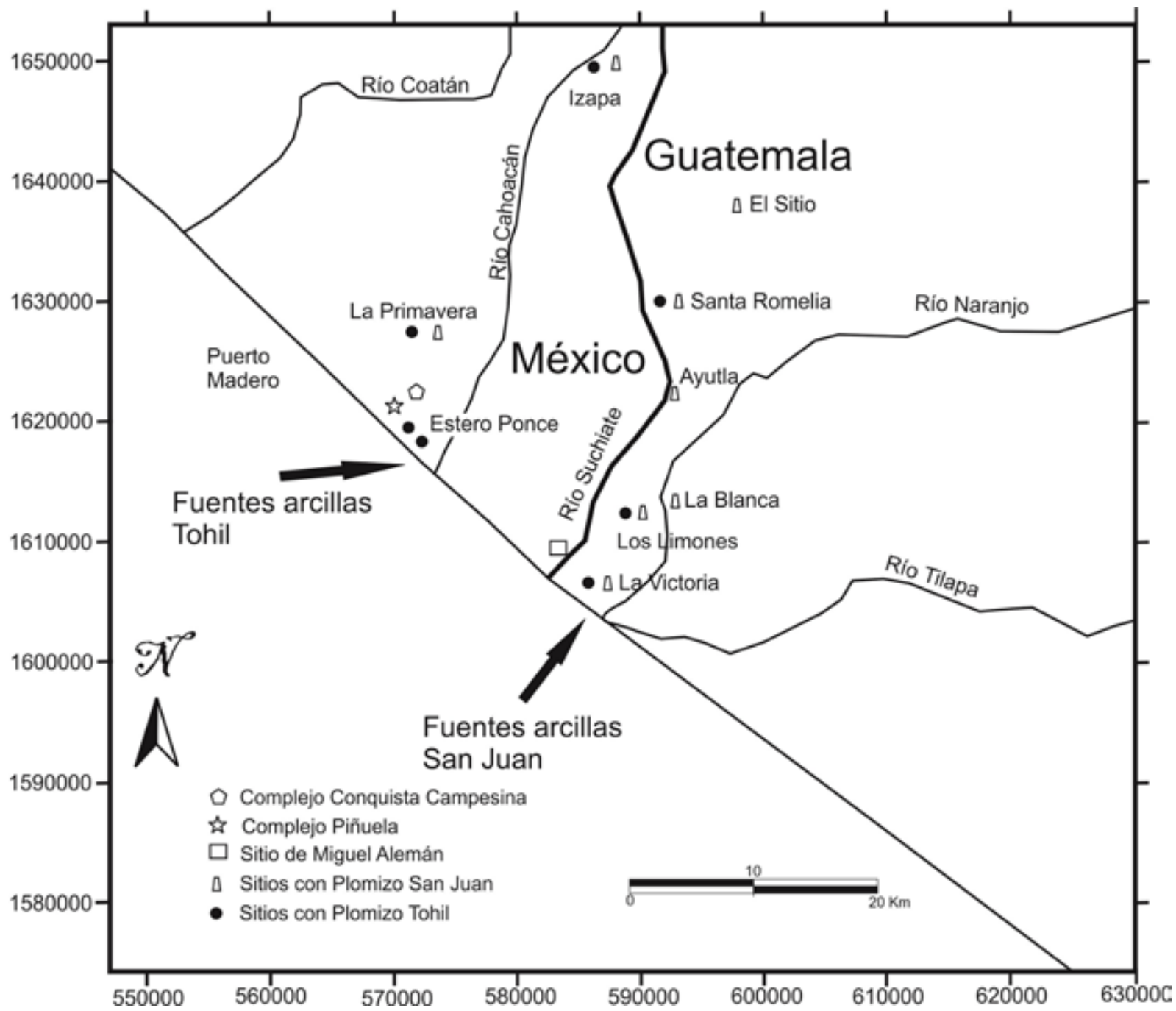

Fuente: imagen cortesía del Proyecto Arqueológico Costa del Soconusco (Hector Neff, director). 
Mapa 2. Ubicación del sitio Miguel Alemán y los complejos Conquista Campesina y Piñuela

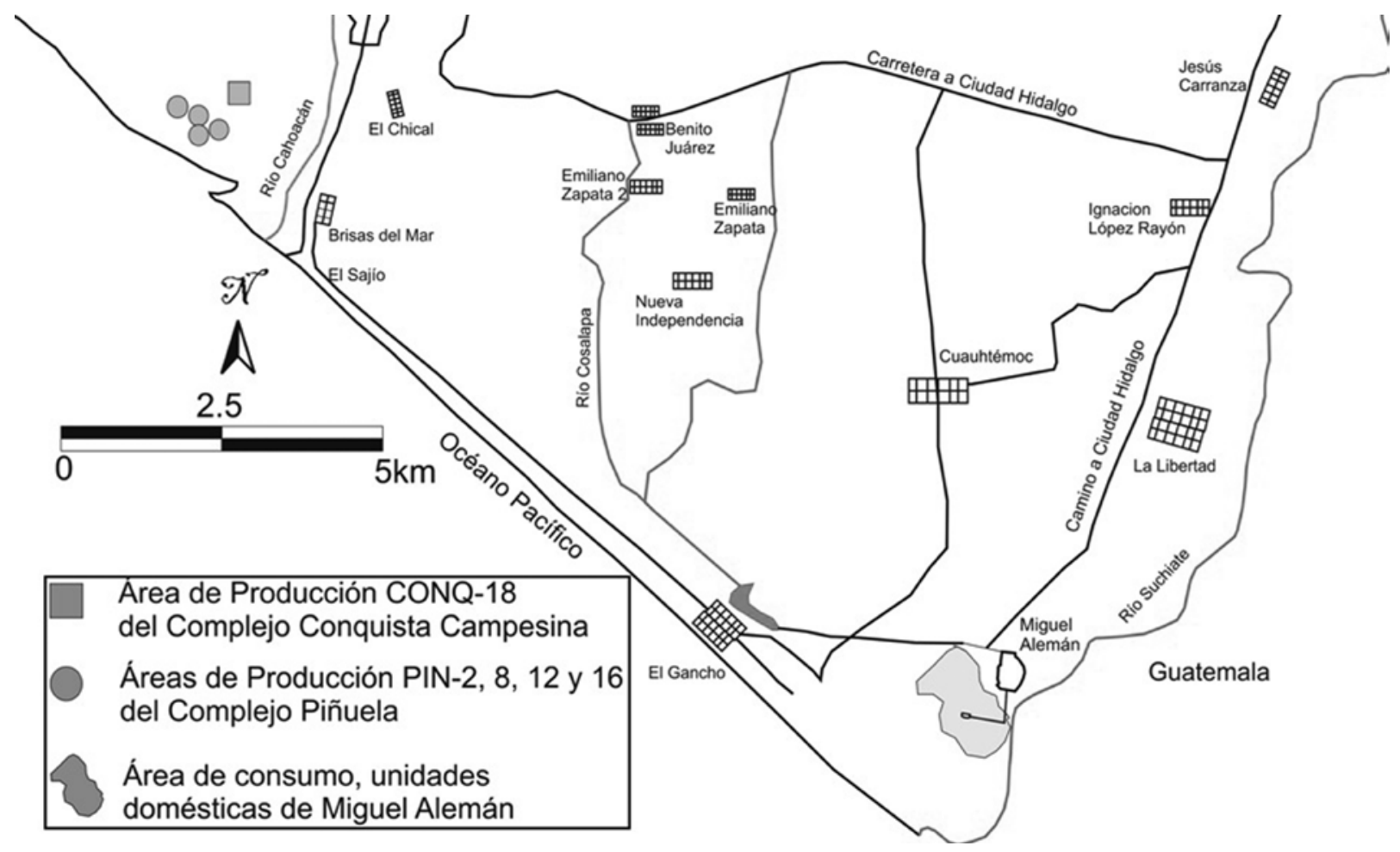

Fuente: información obtenida de INEGI (2013: 3). 